\title{
A comparative study of endoscopic and conventional septoplasty
}

\author{
Mandal S. ${ }^{1}$, Jana S. ${ }^{2 *}$ \\ DOI: https://doi.org/10.17511/ijmrr.2020.i01.01 \\ 1 Soma Mandal, Assistant Professor, Department of ENT and Head-Neck Surgery, Calcutta National Medical College and Hospital, Kolkata, \\ West Bengal, India. \\ 2* Sonali Jana, RMO-cum-Clinical tutor, Department of ENT and Head-Neck Surgery, Calcutta National Medical College and Hospital, \\ Kolkata, West Bengal, India. \\ Objective: Nasal obstruction due to deviated nasal septum is a common problem encountered by \\ otolaryngologist. The standard surgical treatment for symptomatic deviated septum is septoplasty \\ which has gone through several modifications since its inception. Study objectives were to compare \\ the endoscopic and conventional septoplasty and to evaluate the advantage, disadvantage and \\ complication of both the procedures. Materials and Methods: Prospective observational study was \\ conducted in department of ENT and Head-Neck-Surgery of a tertiary care teaching hospital. Sixty \\ patients undergoing either endoscopic septoplasty or conventional septoplasty were studied \\ prospectively for a period of 3 months to compare the efficacy of both the techniques. Objective \\ assessment was done by doing nasal endoscopy 90 days after the operation to note the following \\ points- (1) Persistence of deviation (2) Spur (3) Formation of synechiae (4) Septal perforation. \\ Result: In this study the endoscopic approach showed better overall clinical result as compared to \\ conventional technique with lesser complication. It was noted that endoscopic septoplasty group had \\ minimum blood loss and shorter operative time than conventional method, but difference was not \\ statistically significant. Conclusion: Endoscopic septoplasty was founded with distinct advantage \\ over conventional method due to better illumination, improve accessibility to remote area was \\ founded. Further surgical experience and larger similar studies will help in coming to a greater \\ consensus.
}

Keywords: Deviated Nasal Septum, Endoscopy, Septoplasty

\section{Corresponding Author}

Sonali Jana, RMO-cum-Clinical tutor, Department of ENT and Head-Neck Surgery, Calcutta National Medical College and Hospital, Kolkata, West Bengal, India.

Email: sonalijana2009@gmail.com
How to Cite this Article

Mandal S, Jana S. A comparative study of endoscopic and conventional septoplasty. Int J Med Res Rev. 2020;8(1):1-6.

Available From

https://ijmrr.medresearch.in/index.php/ijmrr/article/ view/1118
To Browse

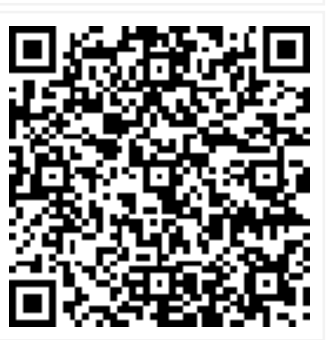

Manuscript Received 2019-12-10

Conflict of Interest No
Review Round 1 2019-12-20

Funding $\mathrm{Nil}$

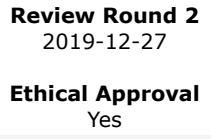

Review Round 3

Plagiarism X-checker $8 \%$
Accepted 2019-12-31

Note

(c) 2020 by Soma Mandal, Sonali Jana and Published by Siddharth Health Research and Social Welfare Society. This is an Open Access article licensed under a Creative Commons Attribution 4.0 International License https://creativecommons.org/licenses/by/4.0/ unported [CC BY 4.0]. 


\section{Introduction}

The asal septum is the bone and cartilage in the nose that separates the nasal cavity into the two nostrils. Normally, the septum lies centrally, and thus the nasal passages are symmetrical. A deviated septum is an abnormal condition in which the top of the cartilaginous ridge leans to the left or the right, causing obstruction of the affected nasal passage. A deviated septum can go undetected for years and thus be without any need for correction. The condition can result in poor drainage of the sinuses and subsequent sinusitis, difficulty in breathing, headache, epistaxis, sleeping disorders such as snoring or sleep apnea [1]. Symptomatic deviated nasal symptom demands surgical correction. Over the decades, various surgical procedures were described by various eminent scientists to correct the deviated nasal septum, starting from radical septal resection to mucosal preservation and subsequent preservation of septal framework. Cottle in 1947 introduced the practice of conservative septal resections. In conventional nasal septal surgery, there is often over exposure, unnecessary manipulation of the septal anatomy and more resection. Relatively poor illumination, accessibility and magnification call for more exposure by a large incision and by elevation of flaps on both sides of the septum. Endoscopic septoplasty is an attractive alternative to traditional septoplasty. Endoscopic septoplasty is a fastdeveloping concept and gaining popularity as it provides a direct - targeted approach to the septal anatomic deformity, allowing a minimally invasive procedure with limited septal mucosal flap dissection and removal of a small cartilaginous and/or bony deformity. Better light visualization and magnification, provided by the endoscope, help to increase the precision of the surgical procedure. Endoscope aids limited but sufficient exposure of septal pathology and there is no need for disarticulation of ethmoidochondral and vomer chondral junctions. Endoscope guided surgery minimizes the dissection area only to the area of deviation and results in less morbidity to the patients. Lanza et al \& Stammberger initially described the application of endoscopic techniques to the correction of septal deformity in 1991 [2,3]. Lanza et al described a detailed endoscopic approach to the treatment of isolated septal spurs also [2]. Giles et al. evaluated the role of endoscopic septoplasty as an adjunct to functional endoscopic sinus surgery [4]. Park et al. concluded
That it is an excellent teaching tool when used in conjunction with video monitors over traditional approaches [5]. Hwang et al. stated that endoscopic septoplasty is helpful in correction of posterior septal deformities, revision cases and as an effective teaching tool [6]. Aims and objectives of the present study are a) To compare the outcomes of endoscopic and conventional septoplasty, b) To evaluate the advantages, disadvantages and complications of both endoscopic and conventional septoplasty.

\section{Materials and Methods}

The study was conducted in the otorhinolaryngology department of a tertiary care teaching hospital, Kolkata, India over a period of one year (January 2016 to December 2017). The study design was prospective randomized one. 60 cases of either sex in age group of 14 to 60 years, having symptomatic deviated nasal septum (DNS) were included in the study.

Inclusion criteria: Subjects with symptomatic deviated nasal septum refractory to conservative medical treatment. Nasal obstruction, postnasal discharge, headache, epistaxis and hyposmia these five symptoms were taken into consideration.

Exclusion criteria: Subjects with allergic/vasomotor rhinitis, nasal mass and nasal polyps, revision cases.

The study was approved by the Institutional Review Board. Informed, written consents were obtained from all individual participants included in the study. All patients were subjected to a detailed clinical history about their symptoms (five symptoms were taken into consideration in this study: nasal obstruction, headache, postnasal drip, hyposmia and epistaxis) and complete ear, nose, throat (ENT) examinations. They were subjected to radiological investigations (X-ray paranasal sinus (PNS)/noncontract computerized tomogram of nose and PNS) to rule out nasal pathology. Detailed nasal endoscopic examination under local anaesthesia (4\% xylocaine with no vasoconstrictors added), using rigid 0 and 30 degree $4 \mathrm{~mm}$ hopkins rod endoscopes, was carried out. Presence of DNS, nasal polyps, turbinate hypertrophy, chronic sinusitis were noted. All the information were recorded in detail in a customized proforma. The patients were randomized by simple randomization with single blinding method into two groups based on the surgical procedure they received. In Group A, 
30 patients underwent endoscopic septoplasty (ES) and in Group B, rest 30 cases underwent conventional septoplasty (CS) under local anaesthesia.

Steps of endoscopic septoplasty: The rigid endoscopes $\left(0^{\circ}\right.$ and $30^{\circ}$ with $4 \mathrm{~mm}$ diameter) were used for the procedure. Xylocaine $2 \%$ with adrenaline infiltration was given on both sides just anterior to deviation. An incision caudal to the deviation on the convex side was made roughly parallel yet cephalic to the classically described hemitrans fixation incision. Mucoperichondrial and mucoperiosteal flaps were raised and deviation whether bony, cartilaginous or combination was visualized. The cartilage was incised parallel but posterior to the flap incision and caudal to the deviation. If the deviation was bony, the incision was made at the bony cartilaginous junction. Mucoperichondrial elevator was inserted through the cartilaginous incision and mucoperichondrial/ mucoperiosteal flap on the opposite side was raised. The deviation was excised. The usual care was taken in preservation of adequate dorsal cartilage to retain the dorsal nasal shape. The flaps were returned to their anatomic position. For septal spurs, an ipsilateral incision was given parallel to the floor of the nose on the apex of the spur. Flaps were elevated superiorly and inferiorly with an elevator to expose the underlying bony or cartilaginous spur. An osteotome was then seated against the base of the spur and used to remove the bony protrusion. Additional remnants of spur were trimmed with through cutting endoscopic forceps. Then flaps were restored to their native position. Nasal cavity was packed with merocels.

Steps of conventional septoplasty: After infiltration with $2 \%$ xylocaine with adrenaline into columella and septum under headlight, incision was made (hemitransfixion) at caudal border. The mucoperichondrial and mucoperoosteal flaps were elevated upto perpendicular plate of ethmoid. The osseocartilaginous junction was dislocated. A $0.5 \mathrm{~cm}$ of the anterior margin of perpendicular plate of the ethmoid was removed with luc's forceps. An inferior cartilaginous strip of $0.5 \mathrm{~cm}$ was removed if necessary. The incision was closed using chromic catgut (3-0) and nasal packing was done.

Intra-operatively following parameters were noted: 1) Duration of surgery, 2) Blood loss during surgery. Patients were given oral antibiotics, analgesics and antihistaminics. They were discharged following pack removal after 48 hrs.
All patients were followed up as outpatients 7, 14, 28 and 90 days after the surgery and were assessed for subjective improvement of their pre-operative symptoms: nasal obstruction, headache, postnasal drip, hyposmia and epistaxis. Subsequently, objective assessment was done by nasal endoscopic examination in the same sitting. Following points were noted during endoscopy:

1) Persistence of deviation or 2) Spur, 3) Formation of synechiae, 4) Septal perforation.

Statistical analysis of the study was done using Chi square test and $\mathrm{p}$ value 0.05 was considered as statistically significant.

\section{Results}

The study included 60 cases. Out of 60 patients, 26 were females (43\%) and 34 were males (57\%). Among 26 females, 13 patients underwent endoscopic and 13 patients underwent conventional septoplasty. Out of 34 males 17 patients underwent endoscopic and 17 patients underwent conventional septoplasty (Table 1 ). The observations showed that the male patients predominated over their female counterpart. The age of the patients ranged from 15 to 60 years. Minimum and maximum age was 16 and 60 years subsequently with mean age 39.17 years and std. deviation 10.731. The majority of our patients were in their third and fourth decades of life (Table 1).

Table-1: Sex incidence and Age distribution among two groups.

\begin{tabular}{|l|l|l|l|l|l|}
\hline \multirow{2}{*}{ Groups } & \multicolumn{2}{|c|}{ SEX } & \multicolumn{3}{c|}{ AGE (in years) } \\
\cline { 2 - 7 } & Male & Female & $15-30$ & $31-45$ & $46-60$ \\
\hline Endoscopic septoplasty & 17 & 13 & 10 & 13 & 7 \\
\hline Conventional septoplasty & 17 & 13 & 3 & 16 & 11 \\
\hline
\end{tabular}

Table-2: pre-operative symptoms among two groups.

\begin{tabular}{|l|l|l|l|l|l|l|}
\hline Symptoms & \multicolumn{2}{|c|}{$\begin{array}{c}\text { Endoscopic } \\
\text { septoplasty group } \\
\mathbf{n}=30\end{array}$} & \multicolumn{2}{|c|}{$\begin{array}{c}\text { Conventional } \\
\text { septoplasty group } \\
\mathbf{n}=30\end{array}$} & Total & $\%$ \\
\hline $\begin{array}{l}\text { Nasal } \\
\text { obstruction }\end{array}$ & $26 / 30$ & $86.6 \%$ & $29 / 30$ & $96.6 \%$ & 55 & 91.6 \\
\hline Headache & $16 / 30$ & $53.3 \%$ & $17 / 30$ & $56.6 \%$ & 33 & 55 \\
\hline $\begin{array}{l}\text { Postnasal } \\
\text { drip }\end{array}$ & $15 / 30$ & $50 \%$ & $15 / 30$ & $50 \%$ & 30 & 50 \\
\hline Hyposmia & $16 / 30$ & $53.3 \%$ & $13 / 30$ & $43.3 \%$ & 29 & 48.3 \\
\hline Epistaxis & $8 / 30$ & $26.6 \%$ & $11 / 30$ & $36.6 \%$ & 19 & 31.6 \\
\hline
\end{tabular}


In the present study, major pre-operative symptom was found to be nasal obstruction $91.66 \%$, followed by Headache $55 \%$, postnasal drip 50\%, Hyposmia $48.33 \%$ and epistaxis $31.66 \%$ (Table 2 ).

It was observed that the mean time taken for conventional septoplasy was 32.03 minutes standard deviation 5.968. On the other hand endoscopic septoplasty required 24.9 minutes standard deviation 4.467 (Table 3). Difference between two groups was not statistically too much significant. Intra operative blood loss: Average blood loss (in $\mathrm{ml}$ ) in the conventional septoplasy (CS) was 87.53 (standard deviation 21.603) while that of endoscopic septoplasty (ES) group was 53.23 (standard deviation 11.6261) (Table 3). Blood loss was more in CS group.

Table-3: Duration and volume of blood loss during surgery:

\begin{tabular}{|l|l|l|l|l|}
\hline \multicolumn{1}{|c|}{ Variable } & \multicolumn{2}{|c|}{$\begin{array}{c}\text { Endoscopic } \\
\text { septoplasty }\end{array}$} & \multicolumn{2}{c|}{$\begin{array}{c}\text { Conventional } \\
\text { septoplasty }\end{array}$} \\
\hline & Mean & Std deviation & Mean & Std. deviation \\
\hline $\begin{array}{l}\text { Duration of surgery } \\
\text { (minute) }\end{array}$ & 24.9 & 4.467 & 32.03 & 5.968 \\
\hline Volume of blood loss (ml) & 53.23 & 11.261 & 87.53 & 21.603 \\
\hline
\end{tabular}

The Post-operative result was analysed by dividing then into subjective \& objective assessment at the end of 90th day. There was significant subjective improvement among patients of both groups. It was noticed that improvement of nasal obstruction was $92.3 \%$, nasal headache $(81.3 \%)$, Postnasal drip (73.3\%) Hyposmia (87.5\%) Epistaxis $(75 \%)$ in endoscopic septoplasty (ES) group. On the other hand in conventional septoplasty group improvement of nasal obstruction (62.1\%), headache $(52.9 \%)$, Post nasal drip (PND) (33.3\%) Hyposmia $(61.5 \%)$ Epistaxis $(63.6 \%)$ was seen (Table 4). This difference in relief of symptom was found to be very significant.

Table-4: Comparison of relief in symptoms in both groups at the end of 90th day

\begin{tabular}{|l|l|l|}
\hline \multicolumn{1}{|c|}{ Symptoms } & \multicolumn{1}{c|}{ Endoscopic group } & \multicolumn{1}{c|}{ Conventional group } \\
\hline Nasal obstruction & $24 / 26(92.3 \%)$ & $18 / 29(62.1 \%)$ \\
\hline Headache & $13 / 16(81.3 \%)$ & $9 / 17(52.9 \%)$ \\
\hline Postnasal drip & $11 / 15(73.3 \%)$ & $5 / 15(33.3 \%)$ \\
\hline Hyposmia & $14 / 16(87.5 \%)$ & $8 / 13(61.5 \%)$ \\
\hline Epistaxis & $6 / 8(75 \%)$ & $7 / 11(63.6 \%)$ \\
\hline
\end{tabular}

On 90th day of follow-up visit, residual deviation was found to be present in $12(40 \%)$ of patient of conventional groups whereas it was present in 2 $(6.7 \%)$ patient of endoscopic group $(P=0.005)$.
In conventional group, $11 \quad(36.7 \%)$ patients developed synechiae whereas in endoscopic group $3(10 \%)$ patients developed synechiae $(P=0.030)$. It was statistically significant (Table 5 ).

Table- 5: Objective assessment in both groups at the end of 90 th day.

\begin{tabular}{|l|l|l|c|}
\hline \multicolumn{1}{|c|}{ Variables } & \multicolumn{1}{|c|}{$\begin{array}{c}\text { Endoscopic } \\
\text { group }(\mathbf{n}=\mathbf{3 0})\end{array}$} & \multicolumn{1}{|c|}{$\begin{array}{c}\text { Conventional } \\
\text { group }(\mathbf{n}=30)\end{array}$} & $\begin{array}{c}\mathbf{P} \\
\text { value }\end{array}$ \\
\hline $\begin{array}{l}\text { Persistence of } \\
\text { deviation }\end{array}$ & $2(6.7 \%)$ & $12(40 \%)$ & 0.005 \\
\hline Persistence of spur & $1(3.3 \%)$ & $5(16.7 \%)$ & 0.195 \\
\hline $\begin{array}{l}\text { Formation of } \\
\text { synechiae }\end{array}$ & $3(10 \%)$ & $11(36.7 \%)$ & 0.030 \\
\hline Septal perforation & $0(0 \%)$ & $2(6.7 \%)$ & 0.492 \\
\hline
\end{tabular}

\section{Discussion}

This study of comparison between conventional septoplasty and endoscopic septoplasty in nasal septal deviations was carried out among 60 patients and they were followed up for a minimum period of 3 months postoperatively. The results were assessed in terms of symptomatic improvement (subjective), endoscopic findings (objective) and post-operative incidence of complication. Further in the present study, the advantage and disadvantage of both endoscopic and conventional septoplasty was tried to be evaluated. In the present study, most common presentation of patient with septal deviation was nasal obstruction (91.6\%) followed by headache (55\%), post-nasal drip (PND) (50\%), Hyposmia (48.33\%) and Epistaxis (31.6\%). The present findings were quite similar to observation of Nayak DR et al [7] where $78.3 \%$ patients had complaint of nasal obstruction. Headache was present in $76.66 \%$, rhinorrhoea in $45 \%$, PND in $58.33 \%$ and hyposmia in $8.33 \%$. In another study conducted by Gulati et al [8] nasal obstruction was complained by $92 \%$ patients, Headache by $58 \%$ patients, catarrh in $50 \%$ patients and post-nasal discharge in $30 \%$. It was observed that the average time taken for ES was (24.9 minute) less as compare to conventional method (32.03 minute) but difference was not statically significant. On assessing the blood less during surgery, it was found that ES had minimal blood loss (mean 52.33) as compare to CS (mean 87.53). A similar experience was obtained by Aiyer [9] who stated that majority of patient $(82 \%)$ who underwent endoscopic septoplasty had minimal $(<50 \mathrm{ml})$ blood loss as compared to $45 \%$ in conventional septoplasty group. At the end of 90 days follow up, there was very significant difference in relief of 
Symptoms among ES and CS group. It was noticed that improvement of nasal obstruction was $92.3 \%$, nasal headache $(81.3 \%)$, Post-nasal drip (73.3\%) Hyposmia (87.5\%) Epistaxis (75\%) in endoscopic septoplasty (ES) group. On the other hand, in conventional septoplasty group improvement of nasal obstruction (62.1\%), headache (52.9\%), Post nasal drip (PND) (33.3\%) Hyposmia (61.5\%) Epistaxis (63.6\%) was seen. Our observations were in consensus with other similar studies. In a study by Harley et al [10] patient with nasal obstruction and headache were selected and significant improvement are observed in endoscopic group as compared to conventional septoplasty group. Gulati et al [8], in their comparative study enrolling 50 cases, stated that $90.5 \%$ cases reported improvement of their obstruction by the endoscopic method while $80 \%$ cases of conventional got relief. This is also in favour of our findings. In a study by Sindhwani \& Wright [11], 54\% patients with complaints of nasal obstruction and facial pain were cured and $38 \%$ showed improvement and $8 \%$ patients were not benefitted. In a study by Harley et al [10] patients with nasal obstruction and headache were selected and significant improvement was observed in endoscopic group as compared to conventional group. These findings are quite similar to ours. Park et al [5] conducted a study on 44 patients to compare the endoscopicassisted correction of deviated nose with that of classical septorhinoplasty. Of the 44 patients, 16 underwent endoscopic-assisted septoplasty and the rest underwent classical septorhinoplasty. The patients' satisfaction was 87.5 and $71.4 \%$, and complications were 0 and $14.3 \%$ for endoscopic and classical approaches respectively. In the present study, ES group of patients showed statistically significant improvement in correction of septal deviation and spur in comparison to CS group. On 90th day of follow-up visit, residual deviation and spur was found to be present in $40 \%$ and $16.7 \%$ of conventional group whereas it was $6.7 \%$ and $3.3 \%$ respectively in endoscopic group. This result is at par with the results of Nayak et al [7]. They showed that only $10 \%$ patients of anterior deviation had persistent septal deformity and posterior deviations/spurs were effectively corrected in most of the cases in endoscopic septoplasty group. They also observed that endoscopic septoplasty was found to be more effective in treating symptoms such as nasal obstruction and headache which is similar to the present results. In the study by Park et al [5] the synechiae were formed in significant lower number of patients in ES qroup as compared
To the CS group. This is in concordance with the current study. In the present study, 11 (36.7\%) patients in conventional group, developed synechiae whereas in endoscopic group $3(10 \%)$ patients developed synechiae. There was slightly more complication in the conventional group (43.4\%) than the endoscopic group $(10 \%)$ in the present study. This is quite similar to the result of Prakash et al [12] where statistically significant higher incidence of complication was observed in the conventional group (35\%) as compare to the endoscopic group (15\%). This result was partly similar to the study of Gupta et al [13], Jain et al [14] and Talluri et al [15]. It was observed that conventional and endoscopic technique were both effective in relieving symptom but endoscopic septoplasty was better than conventional method as endoscope gives better illumination, magnification and improved access to high DNS. It allows limited incision and flap elevation and achieves correction with least resection. This technique causes lesser trauma to septum, thus reduction of post-operative complication. It effectively relieves the contact area thus the contact headache by allowing intraoperative assessment. Similarly, Sousa et al [16] conducted a study to show that endoscopic nasal septal surgery is an easy, effective and quick alternative to conventional septoplasty. However, endoscope has its own limitations which includes loss of binocular vision and need for frequent clearing of the tip of endoscope specially where there is more bleeding [8].

\section{Limitations}

Single centric research and small sample size are the limitations of this study.

\section{Conclusion}

In this study both the conventional and endoscopic septoplasty were found to be very effective in relieving the symptoms, but septoplasty done by endoscopic approach has showed significant better result due to accurate identification of pathology, better illumination, improve accessibility to remote area and magnification. ES is associated with significant reduction in morbidity in post-operative period due to limited extent of flap dehiscence. However, endoscopy has its own limitation which includes loss of binocular vision, frequent cleaning of tip when there is more bleeding and lastly complex deformity can't be corrected. Further surgical experience and larger similar studies will 
Help to overcome the difficulty.

\section{What the study adds to the existing knowledge}

Endoscopic septoplasty shows significant better result than conventional septoplasty due to accurate identification of pathology, better illumination, improve accessibility to remote area and magnification.

\section{Authors' Contribution}

Dr. Soma Mandal: Study design, data analysis, paper writing. Dr. Sonali Jana: Study design, paper writing.

\section{Reference}

01. Pannu KK, Chadda S, Kaur IP. Evaluation of benefits of nasal septal surgery on nasal symptoms and general health. Indian J Otolaryngol Head Neck Surg. 2009;61(1)59-65. doi: [Article] [Crossref]

02. Lanza DC, Kennedy DW, Zinreich SJ. Nasal endoscopy and its surgical application, Essential otolaryngology- head and neck surgery. 5th ed, New York- Mc Graw-Hill Education Europe. 1991;373-387.

[Crossref]

03. Stammberger $H$. Functional endoscopic sinus surgery, The Messer $\mathrm{k}$ linger Technique, Decker BC. Philadelphia- Mosby Inc. 1991;PP 430-434. [Crossref]

04. Giles WC, Gross CW, Abram AC, Greene WM, Avner TG. Endoscopic septoplasty. The Laryngosco. 1994;104(12)1507-1509. doi: [Article] [Crossref]

05. Park DH, Kim TM, Han DG, Ahn KY. Endoscopic assisted correction of the deviated nose. Aesthetic Plast Surg. 1998;22(8)190-195. doi: [Article] [Crossref]

06. Hwang PH, McLaughlin RB, Lanza DC, Kennedy DW. Endoscopic septoplasty- indication, technique, and results. Otolaryngol Head Neck Surg. 1999;120(5)678-682.

doi: [Article] [Crossref]

07. Nayak DR, Balakrishnan R, Murthy KD, Hazarika P. Endscopic Septoturbinoplasy- our update series. Indian J Otolaryngol Head Neck Surg. 2002;54(1)20-24.

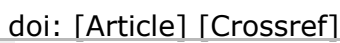

08. Gulati SP, Raman W, Neetika A, Ajay G. Comparative evaluation of endoscopic with conventional septoplasty. Indian J Otolaryngol Head Neck Surg. 2009;61(1)27-29. doi: [Article] [Crossref]

09. Aiyer RG, Raval JB. Comparative Study Between Endoscopic Septoplasty and Conventional Septoplasty. World Articles in Ear, Nose and Throat. 2010;3;1.

[Crossref]

10. Harley DH, Powitzky ES, Duncavage J. Clinical outcomes for the surgical treatment of sinonasal headache. Otolaryngol Head Neck Surg. 2003;129(3)217-221. doi: [Article] [Crossref]

11. Sindhwani R, Wright DE. Role of endoscopic septoplasty in the treatment of atypical facial pain. J Otolaryngol. 2003;32(2)77-79.

[Crossref]

12. Prakash NS, George NM. Endoscopic boon from the Conventional Septoplasty trends. Nat J Otorhinolaryngol Head Neck Surg. 2014;2(2)2224.

[Crossref]

13. Gupta M, Motwani G. Comparative study of endoscopic aided septoplasty and traditional septoplasty in posterior nasal septal deviation. Indian J Otolaryngol Head Neck Surg. 2005;57(4)309-311. doi: [Article] [Crossref]

14. Jain L, Jain M, Chouhan AN, Harshwardhan R. Conventional Septoplasty verses Endscopic Septoplasy- A comparative study. Peoples J Sci Res. $2011 ; 4(2) 24-28$.

[Crossref]

15. Talluri KK, Motru B, Avvaru K, Babu GR, Pradeep JK. Correction of Deviated Nasal SeptumConventional VS Endoscopic Septoplasty. IOSR J Dent Med Sci. 2014;13(5)14-15.

[Crossref]

16. Sousa AD, Inciarte $L$, Levine $H$. Powered Endoscopic Nasal Septal Surgery. Acta Med Port. $2005 ; 18(4) 249-255$.

[Crossref] 